\title{
Osteolytic Lesion with Thick Sclerotic Walls and Demyelinating Polyneuropathy
}

ALEXANDRA FORESTIER, MD, Lille Nord de France University, Department of Internal Medicine, Claude-Huriez Hospital, Regional University Hospital of Lille; GUILLAUME LEFEBVRE, MD, Lille Nord de France University, Department of Musculoskeletal Radiology, Regional University Hospital of Lille; XAVIER LEROY, MD, PhD, Lille Nord de France University, Department of Pathology, Regional University Hospital of Lille; JEREMY HUSSON, MD, Department of Neurology, Regional Hospital of Bethune; JULIE GAY, MD; XAVIER LELEU, MD, PhD, Lille Nord de France University, Department of Hematology, Regional University Hospital of Lille; ERIC HACHULLA, MD, PhD; PIERRE-YVES HATRON, MD, Lille Nord de France University, Department of Internal Medicine, Claude-Huriez Hospital, Regional University Hospital of Lille; DAVID LAUNAY, MD, PhD, Lille Nord de France University, Department of Internal Medicine, Claude-Huriez Hospital, Regional University Hospital of Lille, Lille Nord de France University, Department of Immunology EA2686, Regional University Hospital of Lille, France. Address correspondence to Dr. D. Launay, Service de Médecine Interne, Hôpital Claude-Huriez, Rue Michel Polonovski, CHRU Lille F-59037, Lille Cedex, France. E-mail: launayd@gmail.com. J Rheumatol 2012;39:2175-6; doi:10.3899/jrheum.120734

Systemic symptoms such as organomegaly and endocrine manifestations, in the presence of a peripheral neuropathy, may alert the clinician to POEMS syndrome (polyneuropathy, organomegaly, endocrinopathy, monoclonal gammopathy, and skin changes).

A 30-year-old man was admitted for the recent onset of a demyelinating polyneuropathy. Clinical and laboratory investigations disclosed lower limb edema, hepatosplenomegaly and lymphadenopathy, gynecomastia associated with hyperprolactinemia, hypothyroidism, adrenal and gonadotropic insufficiencies, and bilateral papilledema. Monoclonal gammopathy IgA $\lambda$ was present. POEMS syndrome was suspected. Serum vascular endothelial growth factor (VEGF) level was $953 \mathrm{pg} / \mathrm{ml}$ (normal < 115). Pelvis radiography (Figure 1) showed an expansile osteolytic lesion mainly in the left iliopubic ramus, contrasting with preserved or thickened cortical margins and thick sclerotic intralesional walls. Three other small lytic lesions with a sclerotic rim were observed. Biopsy of the largest bone lesion showed a massive infiltration by atypical plasma cells (Figure 2), which were clonal lambda on immunostaining (Figure 3). POEMS was confirmed and, because there were $>2$ bone lesions, chemotherapy was started, as well as cementoplasty of the large osteolytic lesion ${ }^{1,2}$.

In the presence of a peripheral neuropathy, systemic symptoms such as organomegaly and endocrine manifesta-

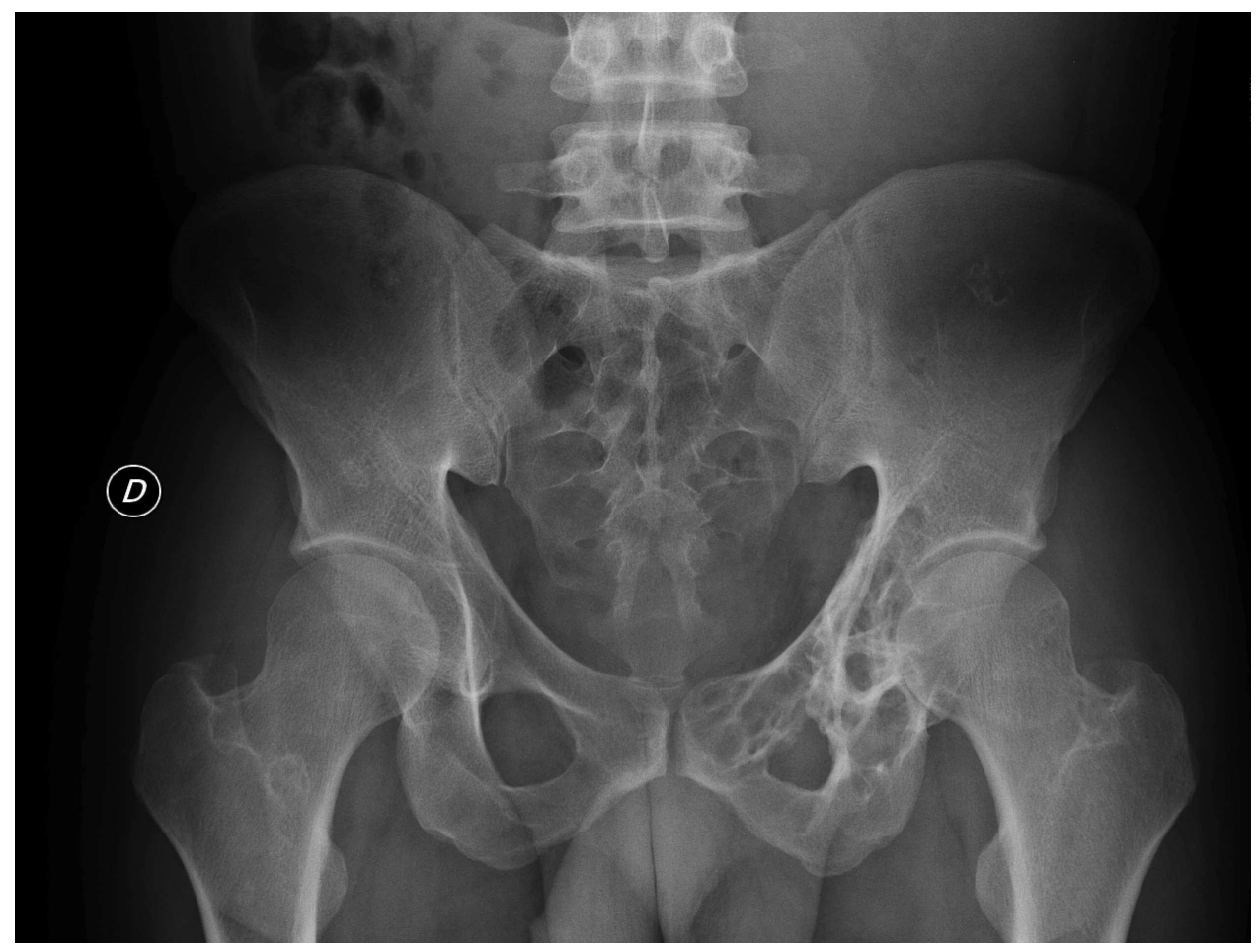

Figure 1. Osteolytic lesion in the left iliopubic ramus with marked thick sclerotic walls.

Personal non-commercial use only. The Journal of Rheumatology Copyright (c) 2012. All rights reserved. 


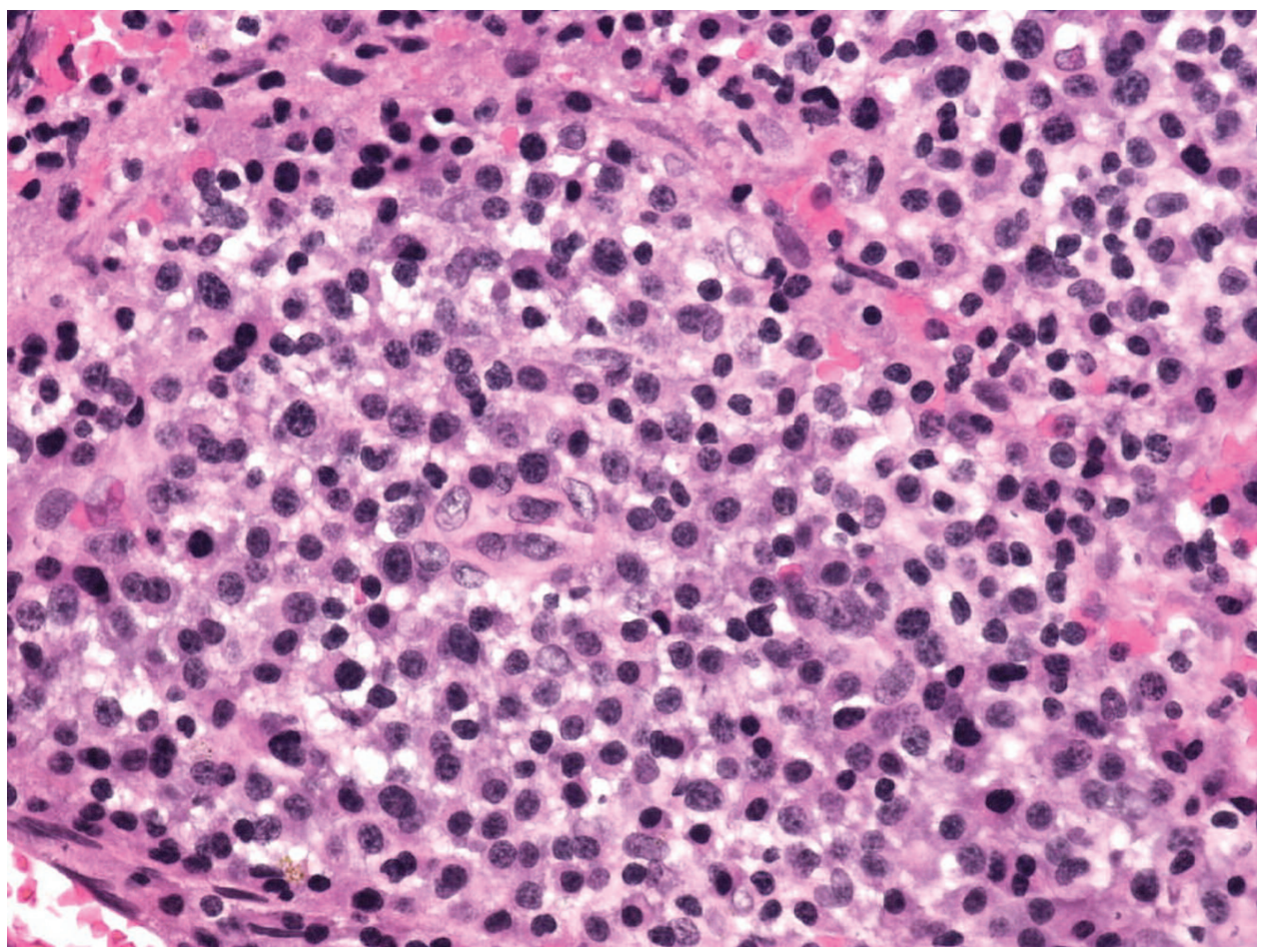

Figure 2. Biopsy showed a massive infiltration by atypical plasma cells (original magnification $\times 400$ )

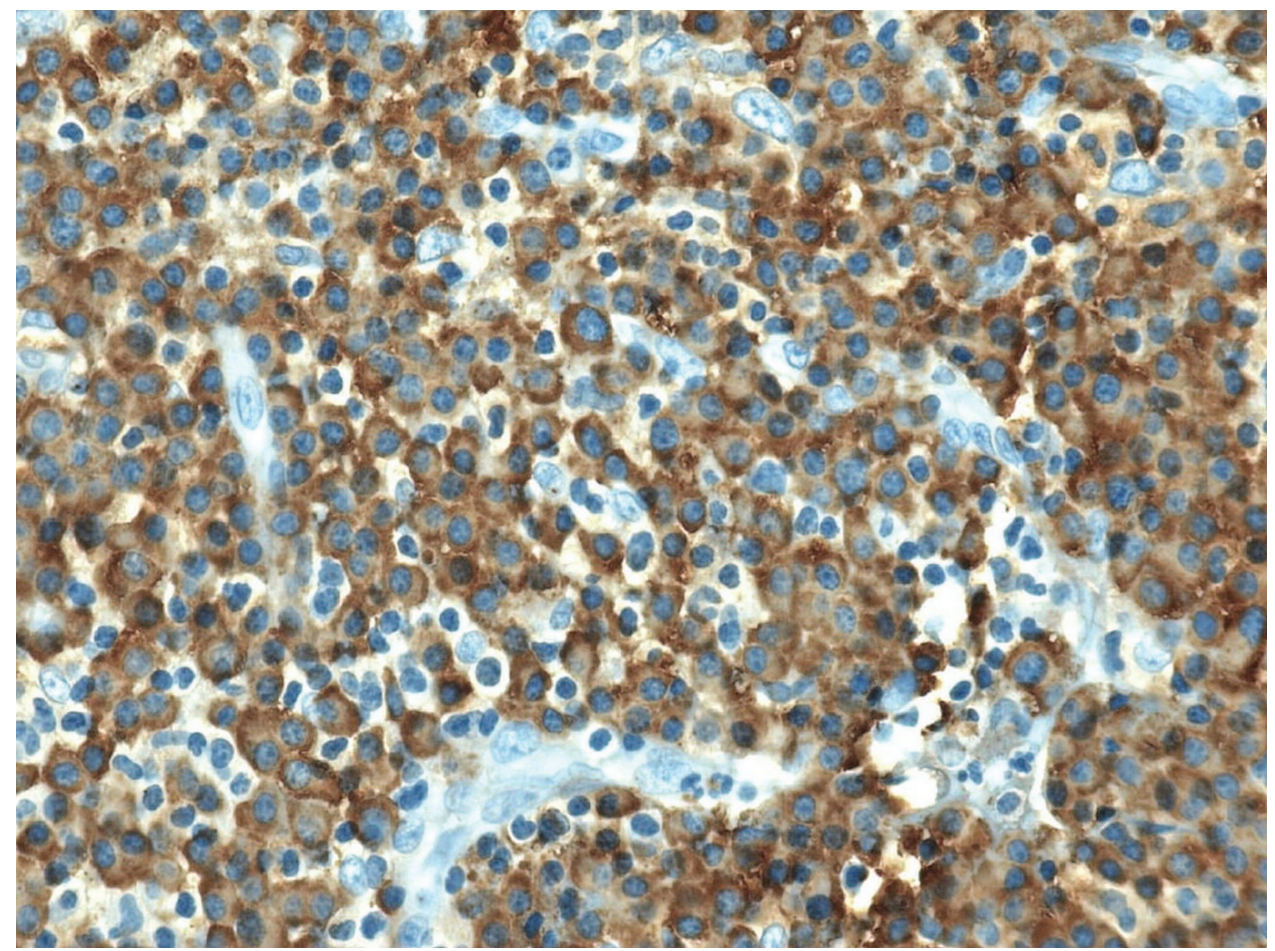

Figure 3. Plasma cells showed clonal lambda on immunostaining (original magnification $\times 400$ ).

tions should suggest POEMS syndrome ${ }^{3}$ and lead to bone radiograph, VEGF serum level measurement, and a search for monoclonal gammopathy.

\section{REFERENCES}

1. Dispenzieri A. POEMS syndrome: 2011 update on diagnosis, risk-stratification, and management. Am J Hematol 2011;86:591-601.
2. Dispenzieri A. How I treat POEMS syndrome. Blood 2012;119:5650-8

3. Bardwick PA, Zvaifler NJ, Gill GN, Newman D, Greenway GD, Resnick DL. Plasma cell dyscrasia with polyneuropathy, organomegaly, endocrinopathy, M protein, and skin changes: the POEMS syndrome. Report on two cases and a review of the literature. Medicine 1980;59:311-22. 